\title{
FIRST BRAZILIAN EXPERIENCE WITH VACUUM- ASSISTED BREAST BIOPSIES GUIDED BY PRONE TOMOSYNTHESIS: 197 CASES
}

Vânia R. M. Sondermann1', Valeska C. Andrade1', Laila Feld', Henrique A. P. Pasqualette1, Paulo M. Soares-Pereira', Marcelo R. Cruz'1, Valéria, R. Cruz¹, Rosana C. R. Santos

${ }^{1}$ Centro de Estudos e Pesquisas da Mulher - Rio de Janeiro (RJ), Brazil.

Objectives: To demonstrate the first Brazilian experience with Prone Tomosynthesis-guided (PTG) vacuum-assisted breast biopsies (VABB) in lesions identified on mammography or tomosynthesis. Material and methods: From November 2018 to February 2019, 197 PTG VABBs in this institution. Results: We retrospectively reviewed 197 PTG VABBs in patients referred from their doctors, with lesions categories 3,4 and 5 BI-RADS ${ }^{\circledR}$, observed in their mammograms or tomosynthesis. The mean age was 54 years (age range 31-90 years). For this we used the Affirm ${ }^{\circledast}$ prone Hologic system, and 9 Gauge dedicated needles. Mean time procedure was 12 minutes (time range 8-17 minutes), shorter than usually with Prone stereotactic vacuum-assisted breast biopsy (22 minutes) and fewer exposures were acquired. The greatest conspicuity area of the lesions were easier to achieve, as well as that lesions identified only on DBT. The clip placement was introduced in the same slice as the lesion was accessed, providing more precision for its location. It's possible to use the Lateral arm to access lesions in very thin breast after compression, and the tomosynthesis of the specimens shows greater number of calcifications than in the digital mammography of them. Conclusion: PTG VABB showed promising results, especially in that cases identified only on DBT and because they can be performed in less time, and less exposures than with the prone stereotactic system. 